\title{
Preventive Effect of Cashew-Derived Protein Hydrolysate with High Fiber on Cerebral Ischemia
}

\author{
Jintanaporn Wattanathorn, ${ }^{1}$ Wipawee Thukham-mee, ${ }^{1}$ Supaporn Muchimapura, ${ }^{1}$ \\ Panakaporn Wannanon, ${ }^{1}$ Terdthai Tong-un, ${ }^{1}$ and Somsak Tiamkao ${ }^{2}$ \\ ${ }^{1}$ Integrative Complementary Alternative Medicine Research and Development Center and Department of Physiology, \\ Faculty of Medicine, Khon Kaen University, Khon Kaen 40002, Thailand \\ ${ }^{2}$ Department of Internal Medicine, Faculty of Medicine, Khon Kaen University, Khon Kaen 40002, Thailand \\ Correspondence should be addressed to Jintanaporn Wattanathorn; jintanapornw@yahoo.com
}

Received 9 August 2017; Revised 7 November 2017; Accepted 21 November 2017; Published 31 December 2017

Academic Editor: Mauro S. Oliveira

Copyright (c) 2017 Jintanaporn Wattanathorn et al. This is an open access article distributed under the Creative Commons Attribution License, which permits unrestricted use, distribution, and reproduction in any medium, provided the original work is properly cited.

\begin{abstract}
This study aimed to determine the protective effect of cashew nut-derived protein hydrolysate with high dietary fiber (AO) in cerebral ischemic rats induced by the occlusion of right middle cerebral artery (Rt.MCAO). Acute toxicity was determined and data showed that $\mathrm{LD}_{50}$ of $\mathrm{AO}>5000 \mathrm{mg} / \mathrm{kg} \mathrm{BW}$. To determine the cerebroprotective effect of $\mathrm{AO}$, male Wistar rats were orally given $\mathrm{AO}$ at doses of 2,10 , and $50 \mathrm{mg} / \mathrm{kg}$ for 14 days and subjected to Rt.MCAO. Brain infarction volume, neurological score, spatial memory, serum lipid profiles, and C-reactive protein together with the brain oxidative stress status were assessed. All doses of AO significantly decreased brain infarction in cortex, hippocampus, and striatum together with the decreased oxidative stress status. The improvement of spatial memory and serum C-reactive protein were also observed in MCAO rats which received AO at all doses. In addition, the decreased serum cholesterol, TG, and LDL but increased HDL were observed in MCAO rats which received high dose of AO. Taken all together, $\mathrm{AO}$ is the potential protectant against cerebral ischemia. The improvement of oxidative stress, inflammation, and dyslipidemia might play roles in the actions. However, further researches are required to understand the precise underlying mechanism.
\end{abstract}

\section{Introduction}

Currently, ischemic stroke has been regarded as an important cause of mortality and morbidity at all economic levels worldwide [1]. However, it mostly occurs in the elderly people and patient outcomes after stroke are highly influenced by age [2]. Ischemic stroke produces the great impacts on the quality of life of both patients and their families. In addition, it also produces a great burden on the annual healthcare budget. Therefore, it has been regarded as one of the important health problems. Despite its importance, the therapeutic efficacy is still limited. Therefore, the safe alternative therapies for longterm prophylaxis are currently required.

Recently, nutrition has been recognized as an important factor for stroke prevention [3]. Several studies have demonstrated that a porcine-derived small peptide, cerebrolysin, can improve many neurological disorders including cerebral ischemia [4-6]. It can decrease apoptosis induced by oxidative stress [7]. Although it can produce a great benefit, it is expensive. Moreover, many of the elderly especially in Asian countries prefer to consume plant derived peptide. In addition to the small peptide, the high fiber food also decreases the risk of stroke [8]. Based on the multitarget approach concept, the benefit of the small peptide with high fiber on brain ischemia has been considered.

Cashew or Anacardium occidentale, a plant in a family of Anacardiaceae, has a great amount of nutrient. The pseudofruit or cashew apple is a rich source of dietary fiber [9] whereas the nut contains abundant protein [10]. Therefore, cashew can be served as the natural resource for developing food supplement targeting at ischemic stroke prevention. Based on the stroke prevention benefit of peptide and dietary fiber mentioned earlier together with the synergistic effect concept, we aimed to develop the cashew-based protein 
hydrolysate with high fiber (AO), a novel stroke protectant food, and to determine the preventive effect of $\mathrm{AO}$ in animal model of ischemic stroke induced by right middle cerebral artery occlusion (Rt.MCAO).

\section{Materials and Methods}

2.1. Preparation of Cashew Nut-Derived Protein Hydrolysate Containing High Fiber. Cashew nuts were cleaned in order to remove all foreign matters such as dust, stone, and dirt, cut into small pieces, and soaked in the boiling water for 10 minutes. Then, distilled water was added at a ratio of $1: 1$ (w/v) and adjusted to $\mathrm{pH} 8$. The suspension was stirred and boiled in water bath at $55^{\circ} \mathrm{C}$ for 30 minutes. The sample was hydrolyzed by adding $2 \%$ alcalase enzyme. After 4 hours of hydrolysis, the inactivation process of enzyme was induced by heating at $90^{\circ} \mathrm{C}$ for 15 minutes in water bath. Then, the mixture was subjected to a 4100-rpm centrifugation for 10 minutes. The supernatant was collected and concentrated by using freeze dryer [11].

In this study, bagasse of cashew was obtained from the waste generated by fruit pulp industrialization and provided by Srisuphaluck Orchid Company, Phuket, Thailand. Cashew apple residue was chopped into small pieces and dissolved in water at a ratio $1: 1(\mathrm{w} / \mathrm{v})$. The suspension was adjusted to $\mathrm{pH}$ 5 , boiled in water bath at $60^{\circ} \mathrm{C}$ for 10 minutes, and filtered through cheese cloth. The filtrate was immersed in $95 \%$ ethanol at room temperature for 24 hours. The mixture was occasionally agitated. This process was repeated twice. Finally, it was dried in oven at $65^{\circ} \mathrm{C}$ and grinded in to powder and used as a sample of dietary fiber [12]. The yielded percentage was $9.09 \%$.

To obtain the desired doses of the cashew nut derived protein hydrolysate with high fiber (AO), the protein hydrolysate at doses of 1,10 , and $100 \mathrm{mg} / \mathrm{kg}$ BW were mixed with dietary fiber at dose of $2 \mathrm{~g} / \mathrm{kg} \mathrm{BW}$.

2.2. DPPH Radical Scavenging Assay. DPPH radical scavenging activity was measured using the method of Cotelle et al. [13] with a slight modification. The total volume of $2.8 \mathrm{ml}$ of tested samples with the concentrations ranging from 5 , $10,25,50,100,250,500$, and $1000 \mu \mathrm{g} / \mathrm{ml}$ was added to each tube which contained $0.2 \mathrm{ml}$ of DPPH $(100 \mu \mathrm{M}$ in methanol), mixed, and incubated at $37^{\circ} \mathrm{C}$ in the dark condition for 30 minutes. The absorbance at $517 \mathrm{~nm}$ was recorded via spectrophotometer. The percentage inhibition of $\mathrm{DPPH}$ radical was calculated by comparing the results of the test with those of the control (not treated with extract) using the following equation:

Percentage inhibition

$$
=\left[1-\frac{\text { A sample }(517 \mathrm{~nm})}{\text { A control }(517 \mathrm{~nm})}\right] \times 100 \text {. }
$$

2.3. Ferric Reducing Antioxidant Power (FRAP) Assay. Reducing power of cashew hydrolysate was performed according to method of Benzie and Strain [14] with some modifications. FRAP reagent which contained $25 \mathrm{~mL}$ of $300 \mathrm{mM}$ acetate buffer ( $\mathrm{pH} 3.6$ ), $2.5 \mathrm{~mL}$ of ferric tripyridyl triazine [Fe(III) (TPTZ)] solution in $40 \mathrm{mM} \mathrm{HCl}$, and $2.5 \mathrm{~mL}$ of $20 \mathrm{mM} \mathrm{FeCl} \cdot 6 \mathrm{H}_{2} \mathrm{O}$ solution was freshly prepared. $10 \mu \mathrm{L}$ of hydrolysate was dissolved in water and was allowed to mix with $1.8 \mathrm{~mL}$ of the FRAP solution at $37^{\circ} \mathrm{C}$ for $10 \mathrm{~min}$. Absorbance of each sample was recorded at $593 \mathrm{~nm}$.

2.4. Evaluation of Cyclooxygenase 2 (COX-2) Inhibition Activity. COX-2 activity was measured using the method of Jang et al. [15] with some modifications. COX-2 activity was assessed by using $\mathrm{N}, \mathrm{N}, \mathrm{N}^{\prime}, \mathrm{N}^{\prime}$-tetramethyl-p-phenylenediamine (TMPD) as a cosubstrate with arachidonic acid (AA). The assay mixture containing heme $(10 \mu \mathrm{L})$, COX -2 $(10 \mu \mathrm{L}), 100 \mu \mathrm{M}$ Arachidonic acid $(20 \mu \mathrm{L}), 10 \mu \mathrm{M} \mathrm{N}, \mathrm{N}_{,} \mathrm{N}^{\prime}, \mathrm{N}^{\prime}$ tetramethyl-p-phenylenediamine (TMPD), and Tris-HCL buffer $\mathrm{pH} 8.00(150 \mu \mathrm{L})$ was mixed with $10 \mu \mathrm{L}$ of various concentrations of sample ranging from 5, 10, 25, 50, 100, 250, 500 , and $1000 \mu \mathrm{g} / \mathrm{ml}$ or indomethacin and incubated at $25^{\circ} \mathrm{C}$ for 30 minutes. Then, the absorbance at $590 \mathrm{~nm}$ was measured using microplate reader. The percentage inhibition of COX2 was calculated by comparing the results of the test with those of the control (not treated with extract) using the following equation:

$$
\begin{aligned}
& \text { Percentage inhibition } \\
& \qquad=\left[1-\frac{\text { A sample }(590 \mathrm{~nm})}{\text { A control }(590 \mathrm{~nm})}\right] \times 100 .
\end{aligned}
$$

2.5. Experimental Animals. Healthy male and female Wistar rats (300-350 g) from the National Laboratory Animal Center, Salaya, Nakhon Pathom, were used as experimental animals. They were randomly housed 5 per cage, maintained in 12:12 light: dark cycle, and given access to food and water ad libitum. The experiments were strictly performed in accordance with the internationally accepted principles for laboratory use and care of the European Community (EEC directive of $1986 ; 86 / 609 / \mathrm{EEC}$ ). The experiment protocols were approved by the Institutional Animal Care and Unit Committee Khon Kaen University, Thailand (Record no. AEKKU 29/2015). All operations were performed under the pentobarbital sodium anesthesia in order to minimize animal suffering.

2.6. Experimental Protocols. Acute toxicity was determined according to the protocols described in OECD Guideline 423. In brief, a total of 20 rats (male 10, female 10) were randomly divided into control and treatment groups. The treatment group was orally given the cashew nut-derived protein hydrolysate with high fiber at a single dose of $5000 \mathrm{mg} / \mathrm{kg}$ BW while control group received vehicle. The general appearance and behavioral changes were recorded at $1,2,4$, and 6 hour-observation period after the daily administration for 14 days. All rats were weighed and we observed mortality, behavioral pattern (salivation, fur, lethargy, and sleep), changes in physical appearance, injury, pain, and signs of illness once daily during the 14-day study period. At the end of study, the blood was collected under anesthesia and the hematological and clinical chemistry changes were 
determined by Srinagarind hospital. After the collection, the principal organs were excised, weighed, and examined both at macroscopic and at microscopic levels. The evaluation at microscopic level was performed via histological study.

In order to determine the cerebroprotective effect of cashew nut-derived protein hydrolysate with high dietary fiber, male Wistar rats (300-350 g) were randomly divided into 7 groups as follows.

Group I. Vehicle + sham operation group: animals in this group were orally given vehicle and received sham operation.

Group II. Vehicle + MCAO group: all rats were orally given vehicle and subjected to the occlusion of right middle cerebral artery.

Group III. Piracetam + MCAO: rats in this group received piracetam, a standard drug claiming for the cerebral blood flow enhancement, at dose of $250 \mathrm{mg} / \mathrm{kg}$ BW via oral route, and were exposed to the occlusion of right middle cerebral artery.

Group IV. Vitamin C + MCAO: the animals in this group received Vitamin C, a well-known antioxidant, at dose of $250 \mathrm{mg} / \mathrm{kg}$ BW via oral route and were exposed to the occlusion of right middle cerebral artery.

Group V-VII. AO + MCAO containing high fiber plus MCAO treated groups: rats in these groups were orally given a cashew nut-derived protein hydrolysate with high fiber at doses of 2 , 10 , and $50 \mathrm{mg} / \mathrm{kg} \mathrm{BW}$ and subjected to the occlusion of right middle cerebral artery.

The animals in groups II-VII were orally given the assigned substances at a period of 14 days and subjected to the occlusion of right middle cerebral artery (Rt.MCAO), whereas animals in group I were treated with vehicle at the same period and exposed to sham operation. All treated substances were continually administered throughout a 21-day study period. The biochemical assays were performed at the end of study.

2.7. Focal Cerebral Ischemic Induction. 12 hours prior to the surgery, animals were exposed to food deprivation but were allowed to access water. Then, they were anesthetized by the intraperitoneal injection of thiopental sodium at dose of $60 \mathrm{mg} / \mathrm{kg}$ BW. After the anesthetization, the occlusion of right middle cerebral artery was induced in all rats (MCAO) as previously described [16]. In brief, the right common carotid artery and the internal carotid artery were exposed through a neck midline incision. A silicone coated nylon monofilament (4-0) suture was gently inserted into the common carotid artery and up to the internal carotid artery for a distance of $17 \mathrm{~mm}$ from the carotid bifurcation. Then, the wound was sutured and the rats were returned to their cages with free access to food and water. The incision sites were infiltrated with $10 \%$ povidone-iodine solution for antiseptic postoperative care. Sham operation groups were exposed to the same operational procedures except the suture which was not advanced into the middle cerebral artery.
2.8. Evaluation of Brain Infarction Volume. All rats were killed 24 hours after MCAO, and the brain was removed and sectioned at 2-mm thickness. Sections were immersed in $2 \%$ TTC (2,3,5-triphenyl tetrazolium chloride) for 30 minutes at $37^{\circ} \mathrm{C}$. The staining brain sections were photographed, and the infarction area was determined by measuring the white area of brain section with computer software (Image J $1.4 \mathrm{~V}$ ).

\subsection{Behavioral Studies}

2.9.1. Neurological Score Assessment. The neurological score was evaluated according to the method of Bederson and coworkers [17]. The grading was performed as described as follows: grade 0: no spontaneous activity, grade 1: spontaneous circling, grade 2: circling if pulled by tail, grade 3 : lowered resistance with lateral push without circling, grade 4: contralateral limb flexion, and grade 5: no apparent deficit.

2.9.2. Assessment of Spatial Memory. Spatial memory was evaluated by using Morris water maze test [18]. A circular pull with a diameter of $170 \mathrm{~cm}$ was filled with water at $40 \mathrm{~cm}$ deep. The top surface was covered with nontoxic powder. The pool was divided into 4 quadrants and the removable platform was immersed at the center of one quadrant. The animal was trained to memorize the location of platform by forming the association between its location and the location of platform by using external cue. The time which the animal spent for finding and climbing on the platform was recorded as escape latency. The immersed platform was removed from its location 24 hours later. The animals were tested again and the mean time spent in the target quadrant in order to search for the missing platform was regarded as the retention time.

2.10. Homogenate Preparation. At the end of experiment, homogenate of right hippocampus, cerebral cortex, and striatum were prepared in $1 \mathrm{~mL}$ of $0.1 \mathrm{M}$ phosphate buffer, $\mathrm{pH}$ 7.4. The obtained brain homogenate was adjusted to $10 \% \mathrm{w} / \mathrm{v}$ and subjected to a $3,000 \mathrm{~g}$-centrifugation (microcentrifuge SIG 1- $15 \mathrm{PK}$ ) at $4^{\circ} \mathrm{C}$ for 15 minutes. The supernatant was harvested and used for further biochemical assessments.

\subsection{Biochemical Analysis}

2.11.1. Malondialdehyde (MDA) Level Assessment. Level of malondialdehyde (MDA) was monitored by using thiobarbituric acid reacting substances (TBARS) assay. In brief, $100 \mu \mathrm{L}$ of sample was mixed with the solution containing $100 \mu \mathrm{L}$ of $8.1 \%(\mathrm{w} / \mathrm{v})$ sodium dodecyl sulphate (Sigma-Aldrich), $750 \mu \mathrm{L}$ of $20 \%(\mathrm{v} / \mathrm{v})$ acetic acid (Sigma-Aldrich) (pH 3.5), and $750 \mu \mathrm{L}$ of $0.8 \%$ thiobarbituric acid (TBA) (Sigma-Aldrich). The solution was heated in a water bath at $95^{\circ} \mathrm{C}$ for one hour and cooled immediately under running tap water. Then, $500 \mu \mathrm{L}$ of chilled water and $2500 \mu \mathrm{L}$ of butanol and pyridine (Sigma-Aldrich) [15:1 v/v] were added to each tube and mixed thoroughly with vortex (Vortex-Genie 2). Then, the solution was centrifuged at $800 \times \mathrm{g}$ for 20 minutes. The upper layer was harvested and the optical density was measured at $532 \mathrm{~nm}$ with spectrophotometer (GENESYS 20). Various concentrations of 1,3,3-tetraethoxypropane (TEP) 
(Sigma-Aldrich) were used as standard [19]. The level of MDA was expressed as $\mathrm{nmol} \cdot \mathrm{mg}^{-1}$ protein.

2.11.2. Determination of Scavenging Enzymes Activities. The determination of superoxide dismutase (SOD) was carried out based on the inhibitory effect of SOD on the reduction of nitroblue tetrazolium (NBT) by the superoxide anion generated by the system xanthine/xanthine oxidase as previously described elsewhere [20]. Absorbance was measured using a spectrometer (UV-1601, Shimadzu) at $550 \mathrm{~nm}$ and the SOD activity was presented as units per milligram of protein ( $\mathrm{Umg} /$ protein). One unit of enzyme activity was defined as the quantity of SOD required to inhibit the rate of reduction of cytochrome by $50 \%$. Catalase (CAT) was performed based on the disappearance of $\mathrm{H}_{2} \mathrm{O}_{2}$ in the presence of brain homogenate at $490 \mathrm{~nm}$ [21]. The activity of CAT was expressed as $\mu \mathrm{mol} \mathrm{H}_{2} \mathrm{O}_{2} / \mathrm{min} / \mathrm{mg}$ protein. Glutathione peroxidase (GSH-Px) was determined using t-butyl hydroperoxide as substrate [22]. The activity was expressed as $\mathrm{U} / \mathrm{mg}$ protein. One unit of the enzyme was defined as micromole $(\mu \mathrm{mol})$ of reduced nicotinamide adenine dinucleotide phosphate (NADPH) oxidized per minute.

2.12. Assessment of Serum C-Reactive Protein. Serum C-reactive protein was determined according to the protocol provided by Thermo Scientific with slight modifications. In brief, $100 \mu \mathrm{L}$ of standard or sample was added per well of the microwell plate. Then, the plate was sealed and incubated overnight at $4^{\circ} \mathrm{C}$ with gentle shaking. After the incubation, the plate was washed 3 times with $350 \mu \mathrm{L}$ of wash buffer. Following the final wash, invert and tap the plate on a paper towel to remove residual buffer. Then, $100 \mu \mathrm{L}$ of diluted HRPconjugated antibody $(1: 100)$ was added to each well of the plate, sealed, and incubated for 1 hour with gentle shaking at room temperature. Following the incubation, each well was washed 3 times with $350 \mu \mathrm{L}$ of wash buffer. Streptavidin solution at the volume of $100 \mu \mathrm{L}$ was added to the reaction mixture, sealed, and subjected to a 45-minute incubation with gentle shaking at room temperature. The solution was removed and the washing was repeated for 3 times. Following this step, $100 \mu \mathrm{L}$ of the TMB substrate solution was added to each well. The reaction mixture was exposed to a 30-minute incubation with gentle shaking at room temperature. The reaction was stopped by adding $50 \mu \mathrm{L}$ of stop solution to each well and the absorbance at $450 \mathrm{~nm}$ was recorded.

2.13. Blood Analysis. Serum preparation was prepared after blood collection. The separation of serum was performed by using cooling centrifugation at 2500 rounds per minute (rpm) for 10 minutes. All serum hematological and clinical chemistry changes were determined using photometric analyzer at Srinagarind hospital, Faculty of Medicine, Khon Kaen University, Khon Kaen, Thailand.

2.14. Statistical Analysis. Data are shown as mean \pm standard error of mean (SEM). Statistical significance was set at $p$ value $<0.05$. Data analysis was performed using ANOVA followed by Tukey post hoc test.
TABLE 1: Amino acid compositions from cashew nut-derived protein hydrolysate.

\begin{tabular}{lc}
\hline Amino acid profiles $(\mathrm{mg} / 100 \mathrm{~g}$ extract $)$ & Cashew nut \\
\hline Alanine & 918 \\
Arginine & $<5.00$ \\
Aspartic acid & 1266 \\
Cystine & 632 \\
Glutamic acid & 3055 \\
Glycine & 784 \\
Histidine & 1823 \\
Hydroxylysine & $<5.00$ \\
Hydroxyproline & 51 \\
Isoleucine & 874 \\
Leucine & 2229 \\
Lysine & 5287 \\
Methionine & 387 \\
Phenylalanine & 2139 \\
Proline & 1011 \\
Serine & 674 \\
Threonine & 414 \\
Tryptophan & 107 \\
Tyrosine & 1064 \\
Valine & 1347 \\
\hline
\end{tabular}

\section{Results}

3.1. Biological Properties and Amino Acid Profiles of CashewDerived Protein Hydrolysate. The biological activities related to the pathophysiology of cerebral ischemia were assessed to evaluate the cerebroprotective potential of the developed product. It was found that the $\mathrm{IC}_{50}$ value of the developed product obtained via DPPH was less than $5 \mu \mathrm{g} / \mathrm{mL}$ while $\mathrm{IC}_{50}$ value of ascorbic acid which was used as positive control was $15.05 \pm 0.36 \mu \mathrm{g} / \mathrm{mL}$. Data obtained from FRAP assay showed that $\mathrm{IC}_{50}$ of the developed product was $4.90 \pm$ $0.01 \mu \mathrm{g}$ ascorbic acid/mg sample. In addition to antioxidant effect, anti-inflammation activity was also assessed via the suppression of cyclooxygenase-2 (COX-2). According to the suppression effect of COX-2, it was revealed that $\mathrm{IC}_{50}$ value of the indomethacin which served as positive control was $50.94 \pm 0.02 \mu \mathrm{g} / \mathrm{mL}$ whereas $\mathrm{IC}_{50}$ of the developed product was less than $5 \mu \mathrm{g} / \mathrm{mL}$. Therefore, our developed product showed high potential of antioxidant and anti-inflammation activities.

The amino acids composition of cashew nut-derived protein hydrolysate in this study was shown in Table 1. Our protein hydrolysate contained abundance of essential amino acids such as lysine, leucine, phenylalanine, and histidine. In addition, it also contained high amount of glutamic acid. Their concentrations were higher than the suggested requirements pattern by FAO/WHO (1990) for adult human. Moreover, the concentration of sulphur containing amino acid such as methionine and cysteine was also very high.

Our data obtained from the amino acid analysis suggested that a cashew nut-derived protein hydrolysate was a high 
TABLE 2: Body weight of rats during a 14-day observation period, after a single administration of cashew nut-derived protein hydrolysate with high fiber at dose of 5,000 $\mathrm{mg} / \mathrm{kg} \mathrm{BW}$ via oral route. ( $N=10 /$ group $)$.

\begin{tabular}{lccc}
\hline Group & \multicolumn{2}{c}{ Body weight (g) } & Percent change of body weight \\
& Day 1 & Day 14 & \\
\hline Male & & & $6.11 \pm 0.004$ \\
$\quad$ Control & $325.40 \pm 1.79$ & $346.20 \pm 1.69$ & $6.10 \pm 0.003$ \\
$\quad$ AO 5,000 mg/kg BW & $327.50 \pm 1.35$ & $347.80 \pm 1.38$ & $5.91 \pm 0.05$ \\
Female & & & $5.67 \pm 0.04$ \\
$\quad$ Control & $227.90 \pm 0.72$ & $241.40 \pm 0.77$ & $247.50 \pm 1.35$ \\
AO 5,000 mg/kg BW & $234.60 \pm 1.35$ & & \\
\hline
\end{tabular}

TABLE 3: Daily food and water intakes of rats during a 14-day observation period, after a single administration of cashew nut-derived protein hydrolysate with high fiber at dose of $5,000 \mathrm{mg} / \mathrm{kg} \mathrm{BW}$ via oral route. ( $N=10$ /group).

\begin{tabular}{|c|c|c|c|c|}
\hline \multirow{2}{*}{ Group } & \multicolumn{2}{|c|}{ Food intake (g/rat/day) } & \multicolumn{2}{|c|}{ Water intake (ml/rat/day) } \\
\hline & Day-1 & Day-14 & Day-1 & Day-14 \\
\hline \multicolumn{5}{|l|}{ Male } \\
\hline Control & $22.68 \pm 0.19$ & $21.09 \pm 4.74$ & $53.40 \pm 0.36$ & $56.50 \pm 0.11$ \\
\hline AO $5000 \mathrm{mg} / \mathrm{kg}$ BW & $23.18 \pm 0.18$ & $21.48 \pm 5.40$ & $50.00 \pm 0.32$ & $55.00 \pm 0.05$ \\
\hline \multicolumn{5}{|l|}{ Female } \\
\hline Control & $14.24 \pm 0.07$ & $14.04 \pm 4.74$ & $56.75 \pm 0.15$ & $55.25 \pm 0.12$ \\
\hline AO $5000 \mathrm{mg} / \mathrm{kg} \mathrm{BW}$ & $14.17 \pm 0.03$ & $14.76 \pm 5.40$ & $55.10 \pm 0.19$ & $53.50 \pm 0.18$ \\
\hline
\end{tabular}

quality food for feeding because it contained abundance of essential amino acids. In addition it also possessed both antioxidant and anti-inflammation activities.

\subsection{Acute Toxicity of Cashew-Derived Protein Hydrolysate} with High Fiber. Our study showed that no abnormal clinical signs, behavioral changes, body weight changes, macroscopic findings, or organ weight changes were observed. It was found that all animals used in this study survived throughout a 14-day study period. The body weight data were shown in Table 2. Both male and female rats showed no significant difference in body weight gain. Table 3 showed that there were no significant differences in both daily food and water intakes of both male and female rats. The single oral administration of cashew hydrolysate with high fiber at dose of $5000 \mathrm{mg} / \mathrm{kg}$ BW also failed to induce the significant organ weight changes as shown in Table 4. In addition, it was found that our data showed no significant changes in hematological and clinical chemistry parameters as shown in Tables 5 and 6.

3.3. Protective Effect against Cerebral Ischemia. Figure 1 showed that MCAO induced brain infarction volume in hippocampus, cerebral cortex, and striatum $(p$ value $<.01$, .001 , and .001 , respectively, compared to vehicle + sham operation group). MCAO rat which received piracetam, a positive control drug used in this study, decreased brain infarction volume in all areas mentioned earlier $(p$ value $<.05$, .001 , and .001, respectively, compared to vehicle + MCAO). The significant reduction in brain infarction volumes in hippocampus and striatum of MCAO rats which received vitamin $C$ treatment was also observed ( $p$ value $<.01$ and .001 , respectively; compared to vehicle $+\mathrm{MCAO})$. Interestingly, all doses of cashew nut-derived protein hydrolysate with high fiber used in this study significantly attenuated the brain infarction volume induced by MCAO in all investigated areas ( $p$ value $<.05$ all; $p$ value $<.001$ all and $p$ value $<.001$ all, compared to vehicle $+\mathrm{MCAO}$ ) as shown in Figure 1 .

3.4. Effect of Cashew-Derived Protein Hydrolysate with High Fiber on Behaviors. The effect of cashew-derived protein hydrolysate with high fiber on neurological score was shown in Figure 2. MCAO rat significantly decreased neurological score at 7, 14, and 21 days after the occlusion of middle cerebral artery ( $p$ value $<.001, .001$, and .01 , respectively, compared to vehicle + sham operation group). MCAO rats which received piracetam significantly increased neurological score at 21 days after treatment ( $p$ value $<.01$, compared to vehicle + MCAO group) whereas MCAO rats which received vitamin C showed the significant increase in neurological score at 14 and 21 days after MCAO ( $p$ value <. 01 all, compared to vehicle + MCAO group). The low dose of cashew nut-derived protein hydrolysate with high fiber failed to improve neurological score while the medium and high doses of the mentioned product significantly improved neurological score ( $p$ value $<$ .01 all, compared to vehicle + MCAO group) .

Figure 3(a) showed that MCAO rats which received vehicle produced a significant increase in escape latency at 7,14 , and 21 days after MCAO ( $p$ value $<.05$ all; compared to sham operation group). Piracetam and Vitamin $C$ mitigated the increase in escape latency in MCAO rats at 7, 14, and 21 days after MCAO ( $p$-value < .01, .001, and .05 all; .05 all, respectively, compared to MCAO + vehicle). MCAO rats which received cashew-derived protein hydrolysate with high fiber at doses of 1,10 and $100 \mathrm{mg} / \mathrm{kg}$ BW produced the significant reduction in escape latency at 7,14 , and 21 days 
TABLE 4: The weight of various organs of male and female rats after a single administration of a cashew nut-derived protein hydrolysate with high fiber at dose of $5,000 \mathrm{mg} / \mathrm{kg}$ BW via oral route. ( $N=10 /$ group $)$.

\begin{tabular}{|c|c|c|c|c|}
\hline \multirow{2}{*}{ Visceral organ (g/kg BW) } & \multicolumn{2}{|c|}{ Male } & \multicolumn{2}{|c|}{ Female } \\
\hline & Control & AO $5000 \mathrm{mg} / \mathrm{kg} \mathrm{BW}$ & Control & AO $5000 \mathrm{mg} / \mathrm{kg}$ BW \\
\hline Brain & $4.12 \pm 0.03$ & $3.89 \pm 0.05$ & $4.96 \pm 0.05$ & $5.09 \pm 0.04$ \\
\hline lung & $4.48 \pm 0.14$ & $3.74 \pm 0.07$ & $5.57 \pm 0.06$ & $5.20 \pm 0.02$ \\
\hline liver & $24.31 \pm 0.08$ & $24.96 \pm 0.52$ & $37.03 \pm 0.38$ & $35.44 \pm 0.13$ \\
\hline Heart & $2.92 \pm 0.03$ & $2.81 \pm 0.02$ & $4.44 \pm 0.04$ & $3.72 \pm 0.14$ \\
\hline Spleen & $2.05 \pm 0.03$ & $1.47 \pm 0.03$ & $2.95 \pm 0.04$ & $2.60 \pm 0.03$ \\
\hline Pancreas & $3.12 \pm 0.09$ & $2.36 \pm 0.22$ & $4.86 \pm 0.14$ & $4.60 \pm 0.22$ \\
\hline Stomach & $4.93 \pm 0.07$ & $5.28 \pm 0.15$ & $7.10 \pm 0.05$ & $6.31 \pm 0.07$ \\
\hline Intestine & $17.99 \pm 0.28$ & $19.33 \pm 0.22$ & $27.32 \pm 0.46$ & $26.04 \pm 0.58$ \\
\hline Thymus gland & $1.07 \pm 0.03$ & $0.92 \pm 0.03$ & $1.63 \pm 0.04$ & $1.76 \pm 0.04$ \\
\hline Urinary bladder & $0.37 \pm 0.01$ & $0.51 \pm 0.01$ & $0.54 \pm 0.01$ & $0.54 \pm 0.00$ \\
\hline \multicolumn{5}{|l|}{ Kidney } \\
\hline Left & $2.78 \pm 0.03$ & $2.65 \pm 0.03$ & $4.11 \pm 0.06$ & $3.67 \pm 0.04$ \\
\hline Right & $2.65 \pm 0.05$ & $2.56 \pm 0.04$ & $4.13 \pm 0.05$ & $3.60 \pm 0.03$ \\
\hline \multicolumn{5}{|l|}{ Adrenal gland } \\
\hline Left & $0.16 \pm 0.00$ & $0.19 \pm 0.01$ & $0.29 \pm 0.02$ & $0.35 \pm 0.00$ \\
\hline Right & $0.13 \pm 0.00$ & $0.14 \pm 0.01$ & $0.38 \pm 0.01$ & $0.42 \pm 0.03$ \\
\hline \multicolumn{5}{|l|}{ Salivary gland } \\
\hline Left & $0.32 \pm 0.01$ & $0.29 \pm 0.01$ & $0.38 \pm 0.01$ & $0.39 \pm 0.02$ \\
\hline Right & $0.33 \pm 0.00$ & $0.28 \pm 0.01$ & $0.36 \pm 0.00$ & $0.26 \pm 0.01$ \\
\hline \multicolumn{5}{|l|}{ Testis/ovary } \\
\hline Left & $3.70 \pm 0.03$ & $3.69 \pm 0.06$ & $1.64 \pm 0.04$ & $1.71 \pm 0.06$ \\
\hline Right & $3.69 \pm 0.05$ & $3.66 \pm 0.04$ & $1.68 \pm 0.04$ & $1.64 \pm 0.06$ \\
\hline
\end{tabular}

TABLE 5: Hematological parameters of experimental rats after a 14-day observation period following a single administration of cashew nutderived protein hydrolysate with high fiber at dose of 5,000 mg/kg BW. ( $N=10 /$ group).

\begin{tabular}{lcccc}
\hline \multirow{2}{*}{ Parameter } & \multicolumn{3}{c}{ Male } & \multicolumn{3}{c}{ Female } \\
& Control & AO 5000 mg/kg BW & Control & AO 5000 mg/kg BW \\
\hline Red blood cell $\left(10^{6} / \mathrm{ul}\right)$ & $8.45 \pm 0.09$ & $8.63 \pm 0.11$ & $8.15 \pm 0.10$ & $8.72 \pm 0.06$ \\
Hemoglobin $(\mathrm{g} / \mathrm{dL})$ & $15.51 \pm 0.09$ & $16.02 \pm 0.15$ & $14.88 \pm 0.17$ & $15.73 \pm 0.14$ \\
Hematocrit $(\%)$ & $43.57 \pm 0.87$ & $45.60 \pm 0.52$ & $43.92 \pm 0.63$ & $47.05 \pm 0.95$ \\
White blood cells $\left(10^{3} / \mathrm{ul}\right)$ & $3.49 \pm 0.34$ & $2.34 \pm 0.19$ & $2.18 \pm 0.34$ & $2.01 \pm 0.19$ \\
Platelet count $\left(10^{3} / \mathrm{ul}\right)$ & $656.57 \pm 61.59$ & $672.40 \pm 20.91$ & $613.00 \pm 39.89$ & $713.75 \pm 22.59$ \\
Neutrophils $(\%)$ & $29.14 \pm 5.46$ & $24.52 \pm 1.80$ & $23.02 \pm 6.51$ & $21.31 \pm 1.75$ \\
Lymphocytes (\%) & $65.43 \pm 4.92$ & $67.46 \pm 2.23$ & $71.30 \pm 7.13$ & $67.50 \pm 1.70$ \\
Monocytes (\%) & $3.90 \pm 1.14$ & $3.50 \pm 0.40$ & $3.40 \pm 0.57$ & $4.19 \pm 0.52$ \\
Eosinophil (\%) & $0.60 \pm 0.15$ & $2.86 \pm 0.94$ & $0.96 \pm 0.11$ & $5.69 \pm 1.92$ \\
Basophil (\%) & $1.00 \pm 0.28$ & $0.46 \pm 0.21$ & $1.32 \pm 0.44$ & $0.56 \pm 0.17$ \\
Mean corpuscular volume (fL) & $55.20 \pm 0.50$ & $54.80 \pm 0.15$ & $53.84 \pm 0.26$ & $51.24 \pm 0.59$ \\
Mean corpuscular Hemoglobin (pg) & $18.26 \pm 0.19$ & $17.76 \pm 0.06$ & $18.28 \pm 0.06$ & $17.75 \pm 0.05$ \\
Mean corpuscular Hemoglobin concentration $(\mathrm{g} / \mathrm{dL})$ & $34.30 \pm 0.15$ & $35.20 \pm 0.33$ & $33.96 \pm 0.11$ & $34.71 \pm 0.40$ \\
Red blood cell distribution width (\%) & $14.87 \pm 0.14$ & $13.86 \pm 0.26$ & $14.40 \pm 0.13$ & $15.04 \pm 0.16$ \\
\hline
\end{tabular}

after MCAO ( $p$ value < .01, .001, and .01; .05 all; .05 all, respectively, compared to $\mathrm{MCAO}+$ vehicle).

The effect of the developed product on retention time was also explored and the results were shown in Figure 3(b). The significant reduction of retention time in MCAO rats was observed at 7 days after MCAO ( $p$-value < .001; compared to sham operation). Piracetam enhanced the retention time in
MCAO rats at 7 days after MCAO ( $p$-value <.01; compared to $\mathrm{MCAO}+$ vehicle group) while vitamin $\mathrm{C}$ increased retention time in MCAO rats after 14 and 21 days after MCAO ( $p$-value $<.01$ all; compared to MCAO + vehicle group). All doses of the developed product significantly increased retention time at 7 and 21 days after MCAO ( $p$ value $<.001$ all; .01, .05, and .05 , respectively; compared to $\mathrm{MCAO}+$ vehicle group). 
TABLE 6: Clinical chemistry parameters of experimental rats after a 14-day observation period following a single administration of cashew nut-derived protein hydrolysate with high fiber at dose of 5,000 mg/kg BW. ( $N=10 /$ group $)$.

\begin{tabular}{|c|c|c|c|c|}
\hline \multirow{2}{*}{ Parameter } & \multicolumn{2}{|c|}{ Male } & \multicolumn{2}{|c|}{ Female } \\
\hline & Control & AO $5000 \mathrm{mg} / \mathrm{kg} \mathrm{BW}$ & Control & AO $5000 \mathrm{mg} / \mathrm{kg} \mathrm{BW}$ \\
\hline Glucose (mg/dl) & $90.40 \pm 1.37$ & $89.60 \pm 0.73$ & $86.60 \pm 1.55$ & $85.40 \pm 0.32$ \\
\hline Cholesterol (mg/dl) & $56.40 \pm 0.72$ & $63.60 \pm 0.52$ & $60.60 \pm 0.69$ & $64.80 \pm 0.73$ \\
\hline Triglyceride (mg/dl) & $72.40 \pm 2.24$ & $77.40 \pm 0.74$ & $68.80 \pm 1.08$ & $68.40 \pm 1.15$ \\
\hline BUN (mg/dl) & $27.51 \pm 0.37$ & $22.70 \pm 0.09$ & $21.72 \pm 0.31$ & $21.42 \pm 0.13$ \\
\hline Creatinine (mg/dl) & $0.40 \pm 0.00$ & $0.38 \pm 0.00$ & $0.38 \pm 0.00$ & $0.42 \pm 0.00$ \\
\hline $\operatorname{ALT}(\mathrm{U} / \mathrm{L})$ & $38.09 \pm 0.74$ & $39.80 \pm 0.50$ & $42.34 \pm 0.40$ & $47.00 \pm 1.33$ \\
\hline $\operatorname{AST}(\mathrm{U} / \mathrm{L})$ & $99.40 \pm 1.87$ & $124.40 \pm 2.40$ & $81.40 \pm 1.71$ & $103.80 \pm 2.74$ \\
\hline $\operatorname{ALP}(\mathrm{U} / \mathrm{L})$ & $29.60 \pm 0.68$ & $27.00 \pm 0.47$ & $32.60 \pm 0.70$ & $30.20 \pm 1.07$ \\
\hline Total Bilirubin (mg/dl) & $0.08 \pm 0.00$ & $0.10 \pm 0.00$ & $0.10 \pm 0.00$ & $0.10 \pm 0.00$ \\
\hline Sodium $(\mathrm{mEq} / \mathrm{L})$ & $140.80 \pm 0.11$ & $138.40 \pm 0.20$ & $140.60 \pm 0.12$ & $142.10 \pm 0.32$ \\
\hline Potassium (mEq/L) & $6.72 \pm 0.08$ & $6.28 \pm 0.09$ & $7.14 \pm 0.07$ & $7.07 \pm 0.11$ \\
\hline Chloride (mEq/L) & $97.00 \pm 0.13$ & $98.60 \pm 0.30$ & $97.40 \pm 0.13$ & $97.30 \pm 0.24$ \\
\hline Bicarbonate $(\mathrm{mEq} / \mathrm{L})$ & $22.78 \pm 0.21$ & $20.20 \pm 0.14$ & $21.15 \pm 0.10$ & $23.35 \pm 0.25$ \\
\hline
\end{tabular}

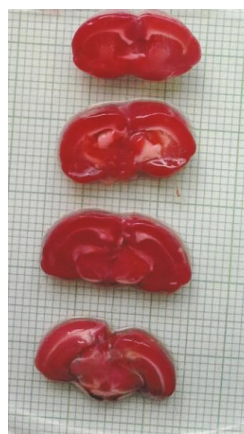

Vehicle + Sham operation

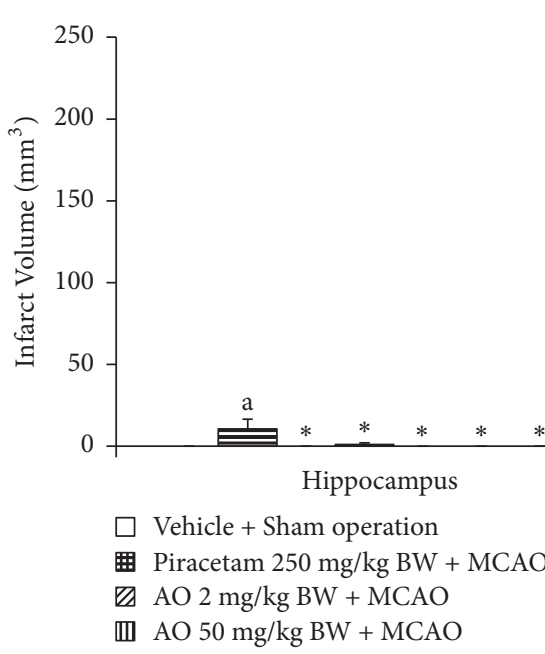

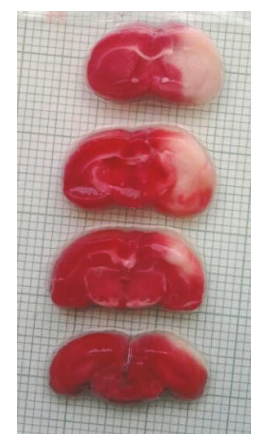

Piracetam + MCAO

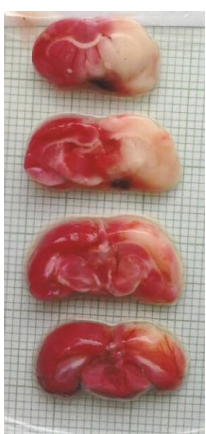

Vitamin C + $\mathrm{MCAO}$

(a)

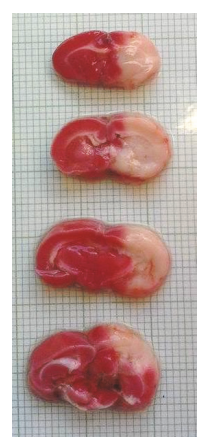

$\mathrm{AO} 2+\mathrm{MCAO}$

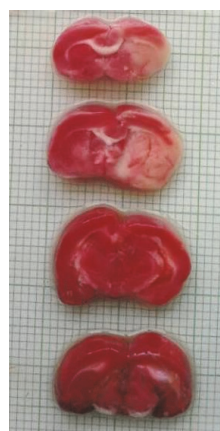

$\mathrm{AO} 10+\mathrm{MCAO}$

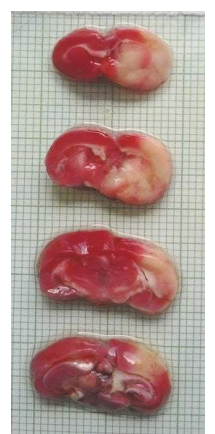

AO $50+$ MCAO

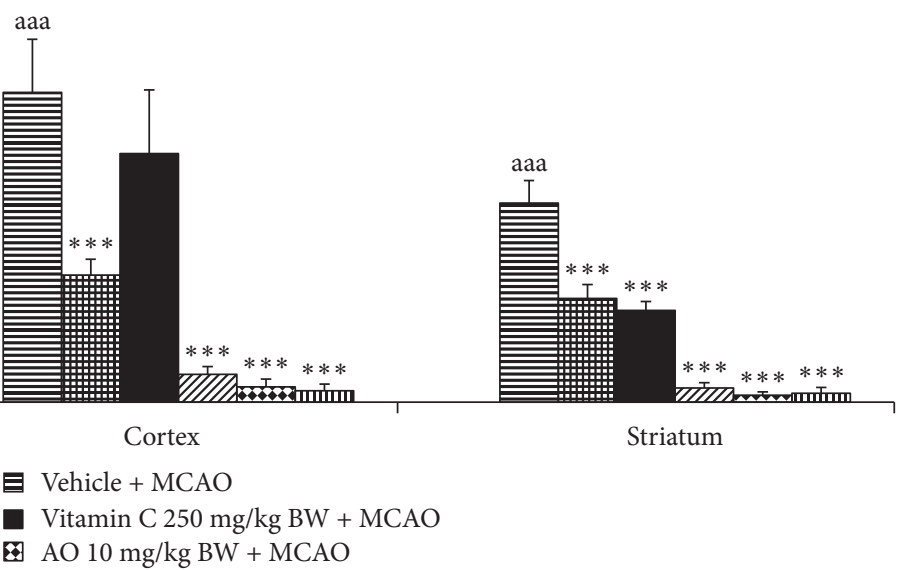

(b)

FIGURE 1: Effect of cashew nut-derived protein hydrolysate with high fiber on brain infarct volume in hippocampus, cerebral cortex, and striatum. (a) Representative photographs of brain infarct volume in various groups assessed by using TTC staining. (b) Volume of brain infarct area, both core and penumbra area of various groups $(N=6 / \text { group })^{\text {a,aaa }} p$ value $<.05$ and .001 , respectively, compared to vehicle + sham operation; ${ }^{*, * * *} p$ value $<.05$ and .001 , respectively, compared to vehicle + MCAO group. 


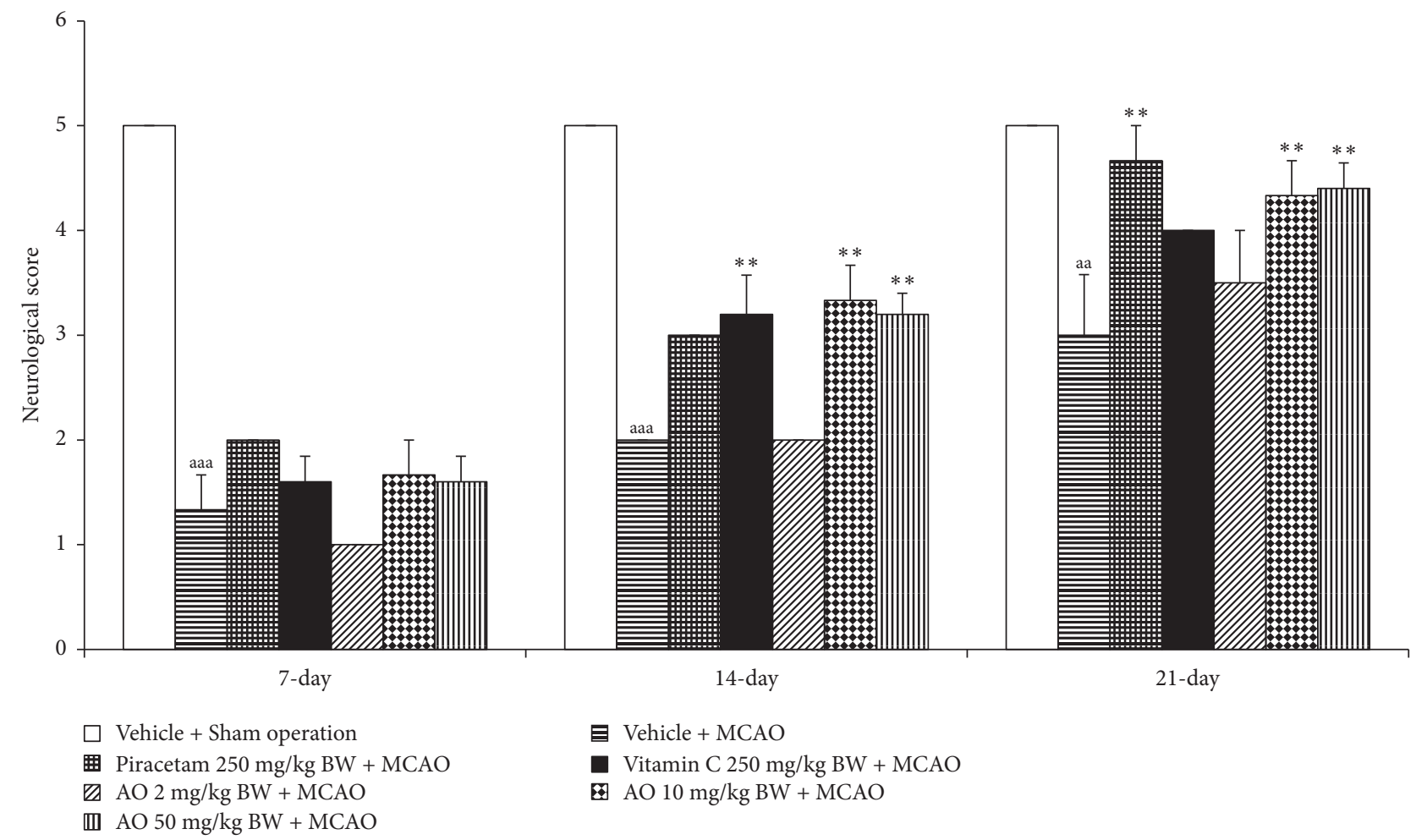

Figure 2: Effect of cashew nut-derived protein hydrolysate with high fiber on neurological score. $(N=6 / \text { group })^{\text {aa,aaa }} p$ value $<.01$ and .001 , respectively, compared to vehicle + sham operation group; ${ }^{* *} p$ value $<.01$, compared to vehicle + MCAO group.

3.5. Brain Oxidative Stress Status. Figure 4 demonstrated that MCAO produced a significant elevation of MDA level in cerebral cortex and striatum $(p$-value $<.001$ all; compared to vehicle + sham operation group). Although the elevation of MDA level in hippocampus was also observed but no significant effect was presented. Both piracetam and vitamin C significantly decreased MDA level in hippocampus ( $p$ value $<.05$ and .01 , respectively; compared to vehicle + MCAO group), cerebral cortex ( $p$-value $<.05$ all; compared to MCAO rats), and striatum ( $p$-value $<.001$ all; compared to vehicle + MCAO group). MCAO rats which received cashew nut-derived protein hydrolysate with high fiber at doses of 2,10 , and $50 \mathrm{mg} \cdot \mathrm{kg} / \mathrm{BW}$ produced the significant reduction MDA level in hippocampus ( $p$-value < .001 all; compared to MCAO + vehicle group), cerebral cortex ( $p$ value $<.05, .01$ and .01 , respectively; compared to vehicle + MCAO group), and striatum ( $p$-value $<.001$ all; compared to vehicle + MCAO group). Since the change of MDA level was under the influence of the enzymatic antioxidant system, we also explored the effect of cashew-derived protein hydrolysate with high fiber on the alterations of main scavenger enzymes including SOD, CAT, and GSH-Px and data were shown in Figures 5-7. In Figure 5, it was found that MCAO significantly decreased SOD activity in cerebral cortex and striatum ( $p$-value < .001 all; compared to vehicle + sham operation grop). Both piracetam and vitamin $\mathrm{C}$ treatments enhanced SOD activity in cerebral cortex and striatum of MCAO rats ( $p$-value < .05 all; compared to MCAO rats). However, cashew nut derived protein hydrolysate with high fiber at all doses used in this study produced the significant elevation of SOD activity in hippocampus, cerebral cortex, and striatum ( $p$-value < .001 all; compared to MCAO rats). Figures 6 and 7 showed that MCAO rats significantly decreased CAT and GSH-Px activities only in cerebral cortex ( $p$-value < .001 and .01, respectively; compared to vehicle + sham operation group). It was found that piracetam induced the significant reduction in CAT activity only in striatum ( $p$ value < .001; compared vehicle + MCAO group) whereas vitamin $C$ produced the significant elevation of CAT activity in both hippocampus and striatum ( $p$-value $<.01$ and .05 , respectively; compared to vehicle $+\mathrm{MCAO}$ group) as shown in Figure 6. The developed protein hydrolysate at all doses used in this study enhanced CAT activity in hippocampus ( $p$-value < .001 all; compared to MCAO rats) and striatum of MCAO rats ( $p$-value $<.001, .5$ and .001 , respectively; compared to vehicle $+\mathrm{MCAO}$ group). Figure 7 demonstrated that both piracetam and vitamin $C$ produced the significant increase in GSH-Px activity only in cerebral cortex ( $p$-value $<.01$ all; compared to vehicle + MCAO group) of MCAO rats. Interestingly, the cashew nut-derived protein hydrolysate with high fiber at all doses used in this study significantly enhanced GSH-Px activity in all areas mentioned earlier ( $p$ value <.001 all; compared to vehicle + MCAO group).

3.6. Inflammatory Marker. Since inflammation plays an essential role on the pathophysiology of cerebral ischemia, we also assessed the effect of the developed product on inflammation by using serum C-reactive protein as index and data 


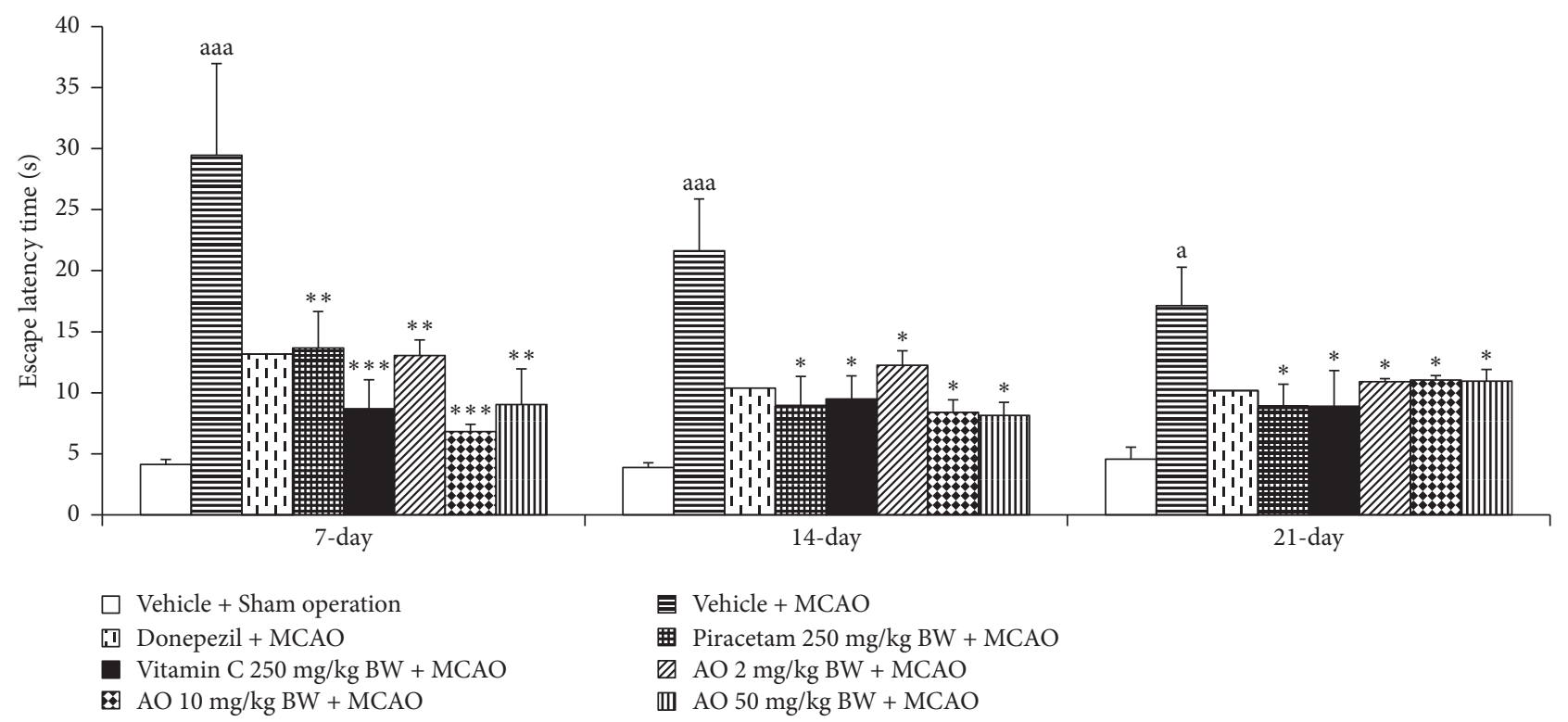

(a)

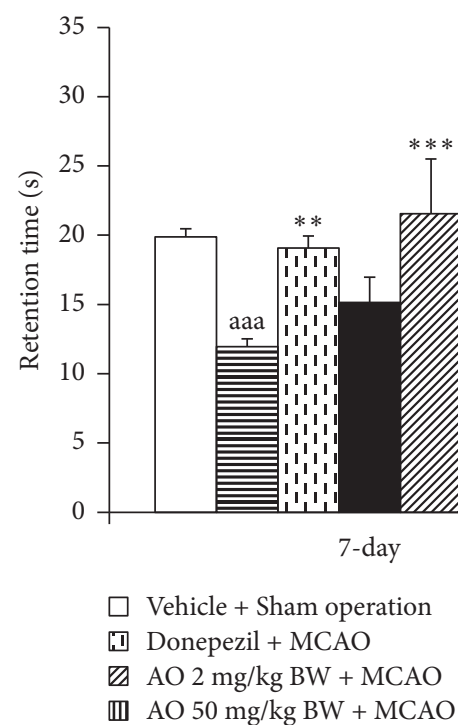

FIGURE 3: Effect of cashew nut-derived protein hydrolysate with high fiber on spatial memory (a) effect on escape latency, (b) effect on retention time. $(N=6 / \text { group })^{\text {a,aaa }} p$ value $<.05$ and .001 , respectively, compared to vehicle + sham operation group; ${ }^{*, * *, * * *} p$ value $<.05, .01$, and .001, respectively, compared to vehicle $+\mathrm{MCAO}$ group.

were shown in Figure 8. MCAO significantly increased serum C-reactive protein $(p$-value $<.001$; compared to vehicle + sham operation group). This elevation was attenuated by piracetam, vitamin $C$, and all doses of the developed product ( $p$-value $<.001$ all; compared to vehicle + MCAO group $).$

3.7. Lipid Profile Changes. Table 7 showed the effect of cashew nut-derived protein hydrolysate with high fiber on lipid profiles. It was found that MCAO rats significantly increased total cholesterol $(p$-value $<.01$; compared to vehicle + sham operation group). MCAO rats which received cashew nut-derived protein hydrolysate with high fiber at dose of $10 \mathrm{mg} / \mathrm{kg}$ BW significantly decreased total cholesterol level
( $p$-value $<.01$; compared vehicle + MCAO group). Interestingly, cashew nut-derived protein hydrolysate with high fiber at dose of $100 \mathrm{mg} / \mathrm{kg}$ BW significantly reduced cholesterol, triglyceride, and LDL but increased HDL $(p$-value $<.01$, $.05, .05$, and .05 , respectively; compared to vehicle + MCAO group).

\section{Discussion}

The present data have demonstrated that single oral administration of cashew hydrolysate with high fiber (AO) at dose of $5000 \mathrm{mg} / \mathrm{kg}$ BW produced no effect on mortality, clinical signs, body weight, and organ weight both in male 


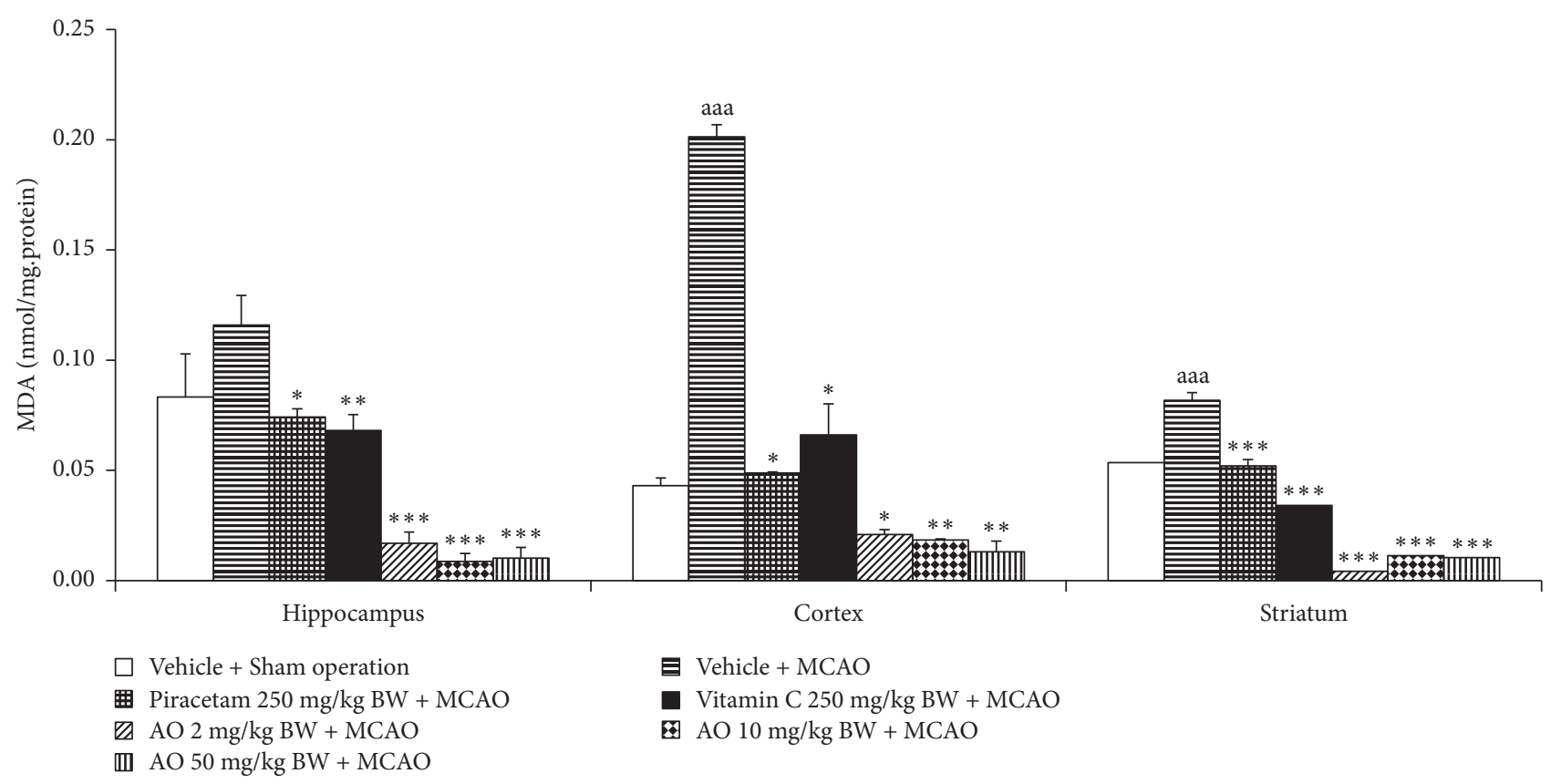

FIGURE 4: Effect of cashew nut-derived protein hydrolysate with high fiber on malondialdehyde (MDA) level in hippocampus, cerebral cortex and striatum. $(N=6 /$ group $){ }^{\text {aaa }} p$ value $<.001$, compared to vehicle + sham operation group; ${ }^{* * * * * * *} p$ value $<.05, .01$, and .001 , respectively, compared to vehicle + MCAO group.

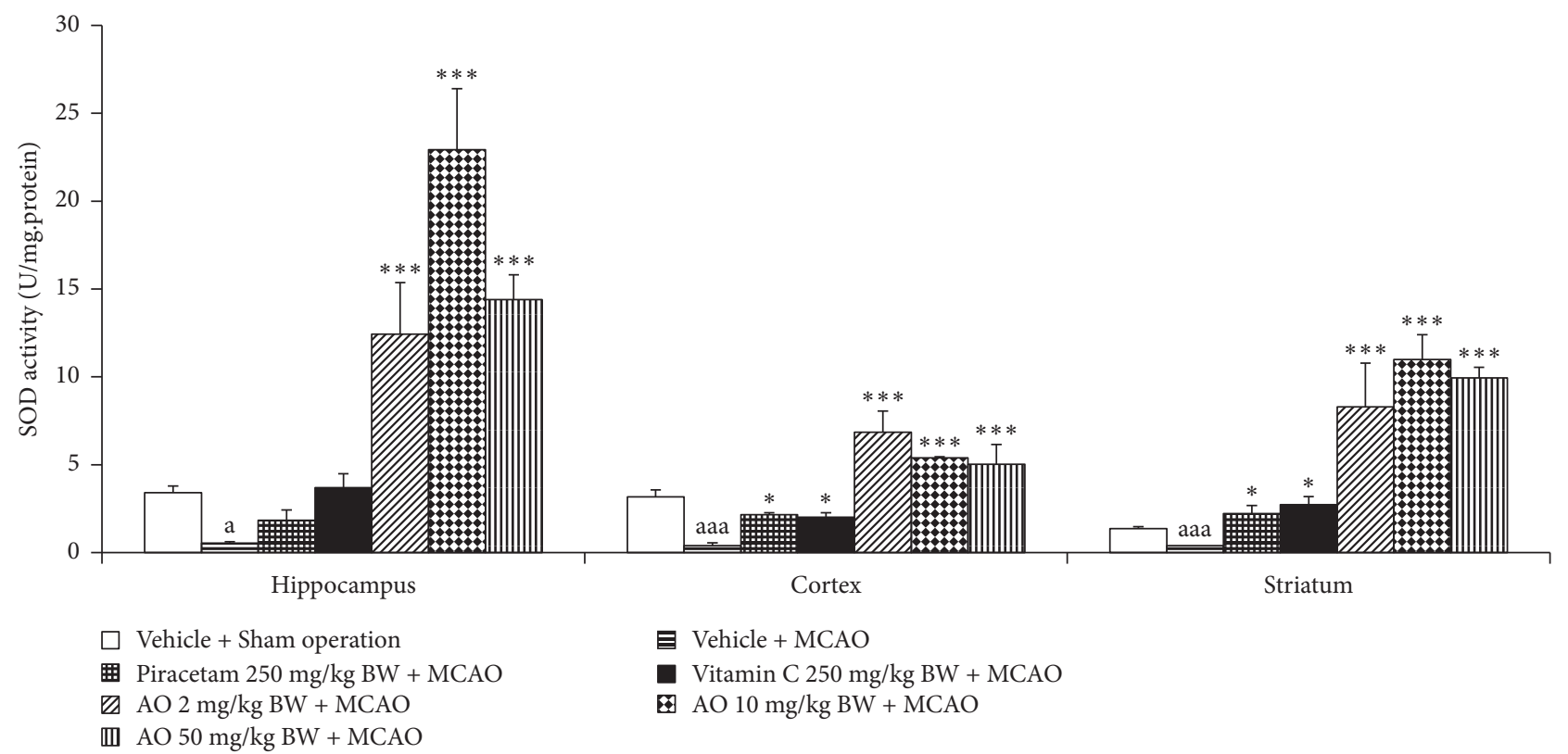

FIGURE 5: Effect of cashew nut-derived protein hydrolysate with high fiber on superoxide dismutase (SOD) activity in hippocampus, cerebral cortex and striatum. $(N=6 \text { /group })^{\text {a,aaa }} p$ value $<.05$ and .001 , respectively, compared to vehicle + sham operation group; ${ }^{*, * * *} p$ value $<.05$ and .001, respectively, compared to vehicle + MCAO group.

and in female rats throughout the 14 days of study period. Therefore, the cashew hydrolysate with high fiber should be classified in category 5 which is recognized as the lowest toxicity class according to the Guidance Document on Acute Oral Toxicity Testing based on oral $\mathrm{LD}_{50}$ value which were recommended by Organization for Economic Cooperation and Development [23-25].
Our in vitro data have clearly demonstrated that $\mathrm{AO}$ shows antioxidant and anti-inflammation activities. These effects are also confirmed by our in vivo data which show that $\mathrm{AO}$ at all doses used in this study enhance the activities of the main scavenger enzymes including SOD, CAT, and GSH-Px. The elevations of SOD and GSH-Px activities are observed in cerebral cortex, hippocampus, and striatum 


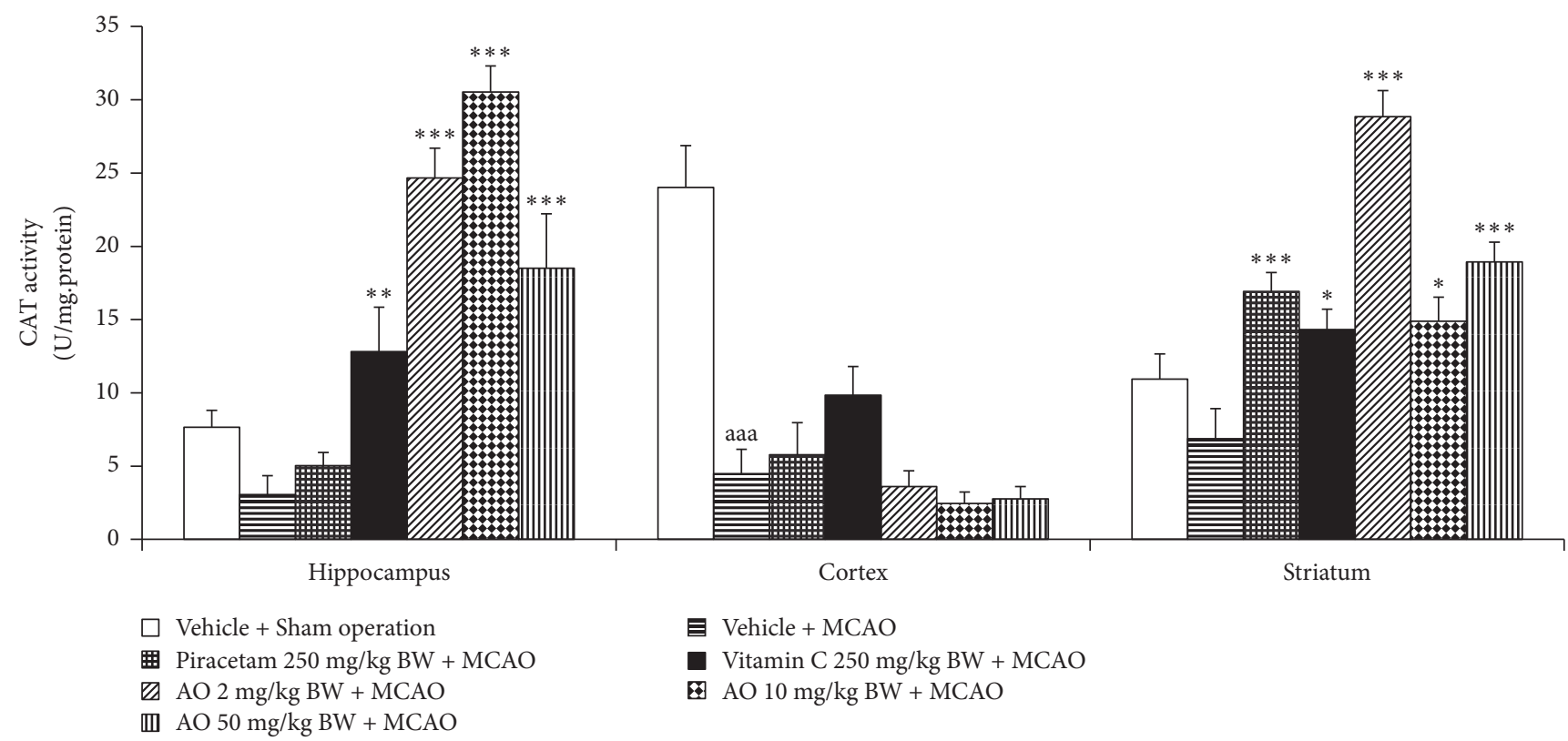

FIGURE 6: Effect of cashew nut-derived protein hydrolysate with high fiber on catalase (CAT) activity in hippocampus, cerebral cortex and striatum. $(N=6 /$ group $){ }^{\text {aaa }} p$ value $<.001$, compared to vehicle + sham operation group; ${ }^{* * * * * * *} p$ value $<.05, .01$, and 001 , respectively, compared to vehicle + MCAO group.

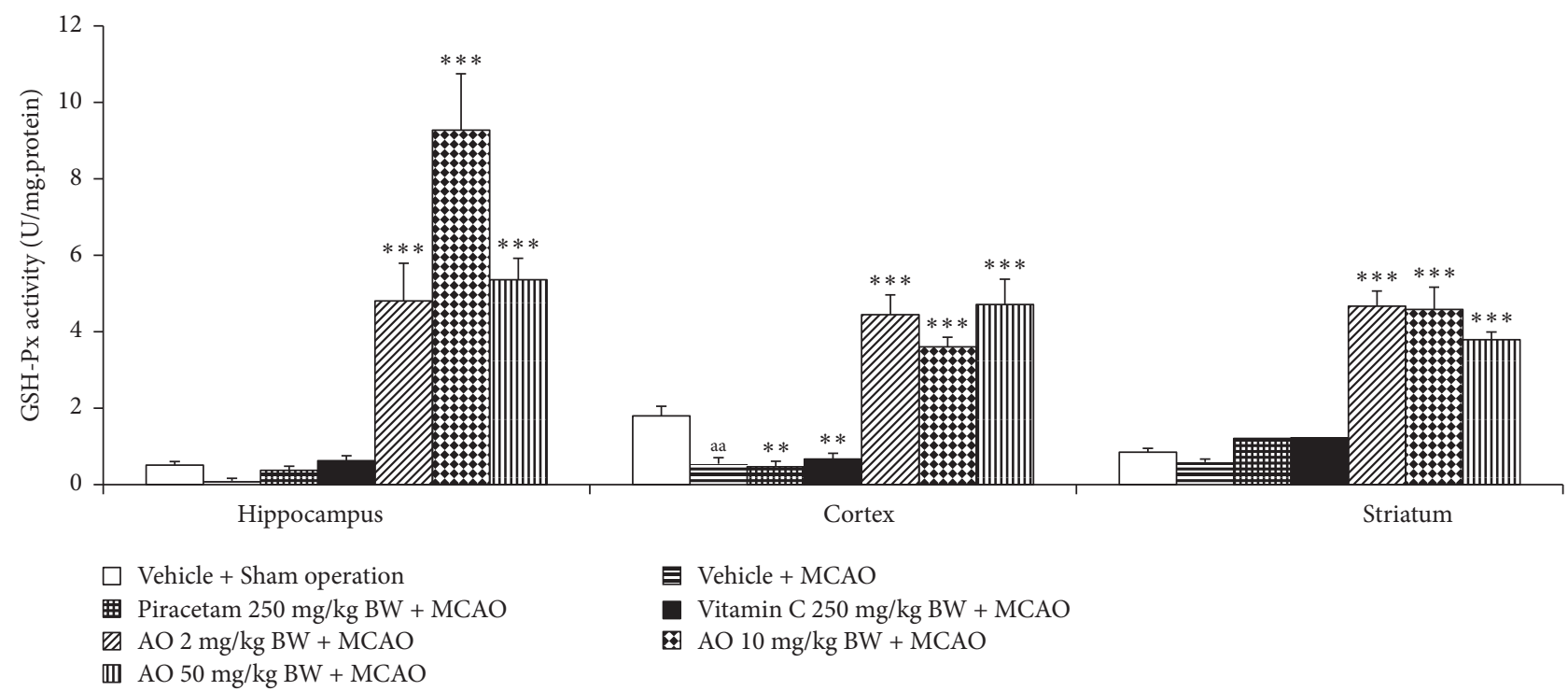

FIGURE 7: Effect of cashew nut-derived protein hydrolysate with high fiber on glutathione peroxidase (GSH-Px) activity in hippocampus, cerebral cortex, and striatum. $\left(N=6\right.$ /group) ${ }^{\text {aa }} p$ value $<.01$ compared to vehicle + sham operation group; ${ }^{* * * * * *} p$ value $<.01$ and .001 , respectively; compared to vehicle + MCAO group.

whereas the enhanced CAT is observed only in hippocampus and striatum. This pointed out CAT activity in cerebral cortex was less sensitive to the treatment. This was in agreement with the previous study which demonstrated that CAT in frontal cortex was less sensitive to pilocarpine treatment [26]. The possible explanation for this phenomenon still required further investigation. The elevation of the scavenger enzymes mentioned earlier may contribute to the important role on the decreased oxidative stress giving rise to the reduction of MDA levels in all brain areas investigated in this study. Since our in vitro data also show that $\mathrm{AO}$ also has the capability of decreasing free radicals by itself, the direct antioxidant effect of AO may also contribute a role. Based on these pieces of information, we suggest that the improved brain infarction in $\mathrm{AO}$ treated rats may be associated partly with the decreased oxidative stress. Recent study had demonstrated that 
TABLE 7: Effect of various doses of cashew nut-derived protein hydrolysate with high fiber on lipid profiles. $(N=6 /$ group $){ }^{\text {aa }} p$ value .01 , compared to vehicle + sham operation group; ${ }^{* * *} p$ value .05 and .01 , respectively, compared to vehicle + MCAO group.

\begin{tabular}{lcccc}
\hline \multirow{2}{*}{ Group } & \multicolumn{3}{c}{ Parameter } \\
& Cholesterol $(\mathrm{mg} / \mathrm{dL})$ & Triglyceride $(\mathrm{mg} / \mathrm{dL})$ & LDL $(\mathrm{mg} / \mathrm{dL})$ & $\mathrm{HDL}(\mathrm{mg} / \mathrm{dL})$ \\
\hline Vehicle + Sham operation & $72.78 \pm 4.97$ & $52.31 \pm 6.28$ & $14.94 \pm 3.39$ & $49.27 \pm 4.40$ \\
Vehicle + MCAO & $92.35 \pm 3.55^{\text {aa }}$ & $72.02 \pm 3.09$ & $21.77 \pm 0.97$ & $43.27 \pm 2.24$ \\
Piracetam 250 mg/kg BW + MCAO & $88.98 \pm 0.32$ & $60.92 \pm 2.13$ & $17.29 \pm 1.45$ & $45.35 \pm 2.54$ \\
Vitamin C 250 mg/kg BW + MCAO & $84.01 \pm 4.62$ & $65.42 \pm 3.21$ & $15.23 \pm 2.63$ & $50.24 \pm 0.54$ \\
AO 2 mg/kg BW + MCAO + MCAO & $85.17 \pm 4.06$ & $70.28 \pm 13.42$ & $15.99 \pm 1.69$ & $47.36 \pm 2.36$ \\
AO 10 mg/kg BW + MCAO + MCAO & $75.44 \pm 4.39^{* *}$ & $56.89 \pm 5.81$ & $17.59 \pm 3.87$ & $53.45 \pm 2.54$ \\
AO 50 mg/kg BW + MCAO + MCAO & $76.70 \pm 2.19^{* *}$ & $46.06 \pm 5.18^{*}$ & $13.04 \pm 2.10^{*}$ & $55.19 \pm 5.66^{*}$ \\
\hline
\end{tabular}
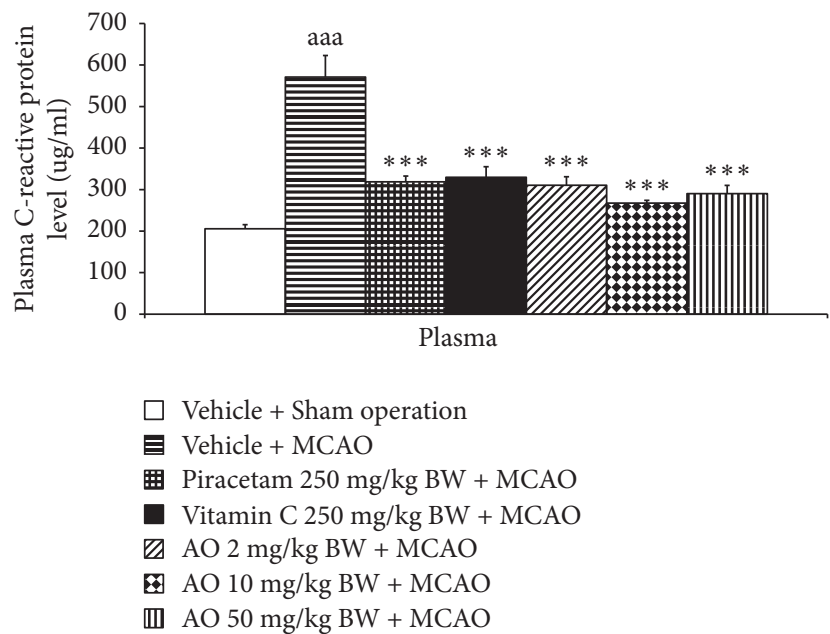

Figure 8: Effect of cashew nut-derived protein hydrolysate with high fiber on serum $C$-reactive protein level. $(N=6$ /group $){ }^{\text {aaa }} p$ value $<.001$ compared to vehicle + sham operation group; ${ }^{* * *} p$ value $<.001$ compared to vehicle + MCAO group.

glutamate and aspartate supplement can alleviate tissue damage induced by oxidative stress [27]. In addition, phenylalanine and sulphur containing amino acids also possess antioxidant activity $[28,29]$. Therefore, the antioxidant effect and the effect to enhance scavenging activity of antioxidant enzymes induced by $\mathrm{AO}$ may partly relate to the presence of these groups of amino acids in AO.

The current data also clearly demonstrated that the cashew nut-derived protein hydrolysate with high fiber also improved neurological score and spatial memory. Based on the previous information that the improved brain infarction was associated with the improvement of neurological score [30] and spatial memory [31], we suggested that the improved neurological score and spatial memory induced by cashew nut-derived protein hydrolysate with high fiber were also associated with the improved brain infarction. In addition, the elevation of serum C-reactive protein also showed positive correlation with brain infarct volume [32]. Recently, it has been shown that cerebral ischemia can stimulate microglia and leukocyte to release inflammatory cytokine such as interleukin-6 (IL-6) [33] which in turn increase the synthesis and release of C-reactive protein into the circulation [34]. The reduction of serum $\mathrm{C}$-reactive protein in $\mathrm{AO}$ treated rats may possibly reflect the reduction of IL- 6 which in turn decreases brain damage and infarction [35]. However, this still further investigation. Based on an anti-inflammatory effect of some amino acid such leucine and isoleucine [36], we suggest that the anti-inflammation of $\mathrm{AO}$ may be associated with the presence of these amino acids in the hydrolysate.

In this study, we also demonstrated that Rt.MCAO rats also showed the elevation of cholesterol. Interestingly, high dose of AO can decrease cholesterol, LDL, and TG but enhance HDL. Since dyslipidemia plays a vital role in the induction of endothelial dysfunction [37] which plays an important role in the pathogenesis of stroke [38], the improved dyslipidemia of AO may also contribute a role on the improvement of brain damage in cerebral ischemic condition especially at high dose treatment. Based on the reputation of dietary fiber on dyslipidemia and inflammation [39], it is possible that the cerebroprotective effect of $\mathrm{AO}$ is associated partly with the effect of dietary fiber content in AO. However, the role of cashew nut- derived protein hydrolysate and the role of the interaction of both cashew nut- derived protein hydrolysate and dietary fiber still cannot be cut off. To provide the precise understanding about the precise underlying mechanisms of the cashew nut-derived protein hydrolysate with high fiber, further researches are essential.

Interestingly, our data showed that $\mathrm{AO}$ at all dosage range used in this study showed the protective effect against cerebral ischemia induced by Rt.MACO better than the positive control or piracetam and vitamin $\mathrm{C}$ especially in cerebral cortex and striatum. Moreover, $\mathrm{AO}$ also improves neurological score, spatial memory, and dyslipidemia better than both substances mentioned earlier. Moreover, it is less toxic. Therefore it is worth further exploring the subchronic toxicity and precise underlying mechanism.

\section{Conclusions}

This study has clearly demonstrated that cashew nut-derived protein hydrolysate with high fiber (AO) is the potential cerebroprotectant against focal cerebral ischemia. The consumption safety is up to $5000 \mathrm{mg} / \mathrm{kg} \mathrm{BW}$. Therefore, it is practically safe. Since it can exert the effect on multitargets simultaneously, it may provide high benefit for the complex disorders such as stroke. However, further researches concerning subchronic toxicity and precise underlying 
mechanisms are required before moving forward to clinical study.

\section{Disclosure}

The founding sponsors had no role in the design of the study, in the collection, analyses, or interpretation of data, in the writing of the manuscript, and in the decision to publish the results.

\section{Conflicts of Interest}

The authors declare no conflicts of interest.

\section{Acknowledgments}

This study was supported by Integrative Complementary Alternative Medicine Research and Development Center, Faculty of Medicine, Khon Kaen University, Thailand, Office of Higher Education Commission and Srisuphaluck Orchid Company through Public-Private Joint Research and Development Project.

\section{References}

[1] V. L. L. C. Feigin, D. A. Bennett, S. L. Barker- Collo, and V. Parag, "Worldwide stroke incidence and early case fatality reported in 56 population-based studies: a systematic review," Lancet Neurology, vol. 8, pp. 355-369, 2009.

[2] R.-L. Chen, J. S. Balami, M. M. Esiri, L.-K. Chen, and A. M. Buchan, "Ischemic stroke in the elderly: an overview of evidence," Nature Reviews Neurology, vol. 6, no. 5, pp. 256-265, 2010.

[3] J. D. Spence, "Nutrition and stroke prevention," Stroke, vol. 37, no. 9, pp. 2430-2435, 2006.

[4] J. M. Wojtowicz, H. Xiong, and A. Baskys, "Brain tissue hydrolysate, Cerebrolysin, acts on presynaptic adenosine receptors in the rat hippocampus," Journal of Neural Transmission Supplementa, no. 47, p. 281, 1996.

[5] W.-D. Heiss, M. Brainin, N. M. Bornstein, J. Tuomilehto, and Z. Hong, "Cerebrolysin in patients with acute ischemic stroke in asia: results of a double-blind, placebo-controlled randomized trial," Stroke, vol. 43, no. 3, pp. 630-636, 2012.

[6] Z. Hong, H. Moessler, N. Bornstein, M. Brainin, and W.-D. Heiss, "A double-blind, placebo-controlled, randomized trial to evaluate the safety and efficacy of cerebrolysin in patients with Acute ischaemic Stroke in Asia - CASTA," International Journal of Stroke, vol. 4, no. 5, pp. 406-412, 2009.

[7] P. Formichi, E. Radi, C. Battisti, G. Di Maio, D. Muresanu, and A. Federico, "Cerebrolysin administration reduces oxidative stress-induced apoptosis in limphocytes from healthy individuals," Journal of Cellular and Molecular Medicine, vol. 16, no. 11, pp. 2840-2843, 2012.

[8] D. E. Threapleton, D. C. Greenwood, C. E. L. Evans et al., "Dietary fiber intake and risk of first stroke: a systematic review and meta-analysis," Stroke, vol. 44, no. 5, pp. 1360-1368, 2013.

[9] L. X. Pinho, M. R. A. Afonso, J. O. B. Carioca, J. M. C. da Costa, and A. M. Ramos, "The use of cashew apple residue as source of fiber in low fat hamburgers," Food Science Technology, vol. 31, no. 4, pp. 941-945, 2011.
[10] S. Ogunwolu, F. Henshaw, H. Mock, and A. Matros, "Production of protein concentrate and isolate from cashew (Anacardium occidentale L.) nut," African Journal of Food, Agriculture, Nutrition and Development, vol. 10, no. 5, pp. 2501-2514, 2010.

[11] M. Muzaifa, N. Fafriani, and F. Zakaria, "Production of protein hydrolysate from fish byproduct prepared by enzymatic hydrolysis," Aqaculture, Aquarium Conservation and Legistration International Journal of the Bioflux Society, vol. 5, no. 1, pp. 36-39, 2012.

[12] T. Prakongpan, A. Nitithamyong, and P. Luangpituksa, "Extraction and application of dietary fiber and cellulose from pineapple cores," Journal of Food Science, vol. 67, no. 4, pp. 1308-1313, 2002.

[13] N. Cotelle, J. L. Bernier, J. P. Pommery, J. C. Wallet, and E. M. Gaydou, "Antioxidant properties of hydroxy-flavones," Free radical Biology Medicine, vol. 20, pp. 35-43, 1996.

[14] I. F. F. Benzie and J. J. Strain, "The ferric reducing ability of plasma (FRAP) as a measure of 'antioxidant power': the FRAP assay," Analytical Biochemistry, vol. 239, no. 1, pp. 70-76, 1996.

[15] M. Jang, L. Cai, G. O. Udeani et al., "Cancer chemopreventive activity of resveratrol, a natural product derived from grapes," Science, vol. 275, no. 5297, pp. 218-220, 1997.

[16] E. Z. Longa, P. R. Weinstein, S. Carlson, and R. Cummins, "Reversible middle cerebral artery occlusion without craniectomy in rats," Stroke, vol. 20, no. 1, pp. 84-91, 1989.

[17] J. B. Bederson, L. H. Pitts, and M. Tsuji, "Rat middle cerebral artery occlusion: evaluation of the model and development of a neurologic examination," Stroke, vol. 17, no. 3, pp. 472-476, 1986.

[18] R. G. M. Morris, P. Garrud, J. N. P. Rawlins, and J. O'Keefe, "Place navigation impaired in rats with hippocampal lesions," Nature, vol. 297, no. 5868, pp. 681-683, 1982.

[19] H. Ohkawa, N. Ohishi, and K. Yagi, "Assay for lipid peroxides in animal tissues by thiobarbituric acid reaction," Analytical Biochemistry, vol. 95, no. 2, pp. 351-358, 1979.

[20] Y. Sun, L. W. Oberley, and Y. Li, "A simple method for clinical assay of superoxide dismutase," Cliniccal Chemistry, vol. 34, no. 3, pp. 497-500, 1988.

[21] L. Góth, "A simple method for determination of serum catalase activity and revision of reference range," Clinica Chimica Acta, vol. 196, no. 2-3, pp. 143-151, 1991.

[22] J. T. Rotruck, A. L. Pope, H. E. Ganther, A. B. Swanson, D. G. Hafeman, and W. G. Hoekstra, "Selenium: biochemical role as a component of glatathione peroxidase," Science, vol. 179, no. 4073, pp. 588-590, 1973.

[23] D. Lorke, "A new approach to practical acute toxicity testing," Archives of Toxicology, vol. 54, no. 4, pp. 275-287, 1983.

[24] 2001, Organisation for Economic Co-operation and Development. Guidance document on acute oral toxicity testing. Organization for Economic Co-operation and Development, Paris, http://ntp.niehs.nih.gov/iccvam/suppdocs/feddocs/oecd/ oecd-gd24.pdf.

[25] J. Duan, J. Yin, W. Ren et al., "Dietary supplementation with 1glutamate and l-aspartate alleviates oxidative stress in weaned piglets challenged with hydrogen peroxide," Amino Acids, vol. 48, no. 1, pp. 53-64, 2016.

[26] R. M. Freitas, V. S. Nascimento, S. M. M. Vasconcelos, F. C. F. Sousa, G. S. B. Viana, and M. M. F. Fonteles, "Catalase activity in cerebellum, hippocampus, frontal cortex and striatum after status epilepticus induced by pilocarpine in Wistar rats," Neuroscience Letters, vol. 365, no. 2, pp. 102-105, 2004. 
[27] A. Masek, E. Chrszescijanska, and M. Zarbosi, "Estimation of antioxidant properties of amino acids-An electrochemical approach," vol. 9, pp. 7904-7915, 2014.

[28] G. Atmaca, "Antioxidant effects of sulfur-containing amino acids," Yonsei Medical Journal, vol. 45, no. 5, pp. 776-788, 2004.

[29] H. Ormstad, H. C. D. Aass, N. Lund-Sørensen, K.-F. Amthor, and L. Sandvik, "Serum levels of cytokines and C-reactive protein in acute ischemic stroke patients, and their relationship to stroke lateralization, type, and infarct volume," Journal of Neurology, vol. 258, no. 4, pp. 677-685, 2011.

[30] W. Kirisattayakul, J. Wattanathorn, T. Tong-Un, S. Muchimapura, P. Wannanon, and J. Jittiwat, "Cerebroprotective effect of Moringa oleifera against focal ischemic stroke induced by middle cerebral artery occlusion," Oxidative Medicine and Cellular Longevity, vol. 2013, Article ID 951415, 10 pages, 2013.

[31] J. Wattanathorn, J. Jittiwat, T. Tongun, S. Muchimapura, and K. Ingkaninan, "Zingiber officinale mitigates brain damage and improves memory impairment in focal cerebral ischemic rat," Evidence-Based Complementary and Alternative Medicine, vol. 2011, Article ID 429505, 8 pages, 2011.

[32] A. Borah, R. Paul, S. Choudhury et al., "Neuroprotective potential of silymarin against CNS disorders: Insight into the pathways and molecular mechanisms of action," CNS Neuroscience \& Therapeutics, vol. 19, no. 11, pp. 847-853, 2013.

[33] S. Chandrashekara, "C - reactive protein: An inflammatory marker with specific role in physiology, pathology, and diagnosis," International Journal of Rheumatology and Clinical Immunology, vol. 2, no. S1, 2014.

[34] R. Shirley, E. N. Ord, and L. M. Work, "Oxidative stress and the use of antioxidants in stroke," Antioxidants, vol. 3, no. 3, pp. 472501, 2014.

[35] R. N. Saxena, V. K. Pendse, and N. K. Khanna, "Anti-inflammatory and analgesic properties of four amino-acids," Indian Journal of Physiology and Pharmacology, vol. 28, no. 4, pp. 299305, 1984.

[36] A. J. Van Boven, J. W. Jukema, and R. Paoletti, "Endothelial dysfunction and dyslipidemia: possible effects of lipid lowering and lipid modifying therapy," Pharmacological Research, vol. 29, no. 3, pp. 261-272, 1994.

[37] P. Rajendran, T. Rengarajan, J. Thangavel et al., "The vascular endothelium and human diseases," International Journal of Biological Sciences, vol. 9, no. 10, pp. 1057-1069, 2013.

[38] M. Viuda-Martos, M. C. López-Marcos, J. Fernández-López, E. Sendra, J. H. López-Vargas, and J. A. Perez-Álvarez, "Role of fiber in cardiovascular diseases: A review," Comprehensive Reviews in Food Science and Food Safety, vol. 9, no. 2, pp. 240258, 2010.

[39] S. J. Miller, A. K. Batra, G. E. Shearrer et al., "Dietary fibre linked to decreased inflammation in overweight minority youth," Pediatric Obesity, vol. 11, no. 1, pp. 33-39, 2016. 

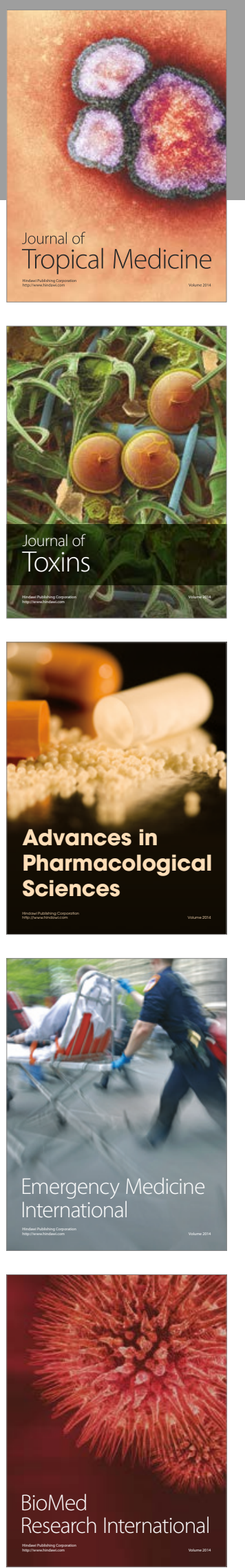
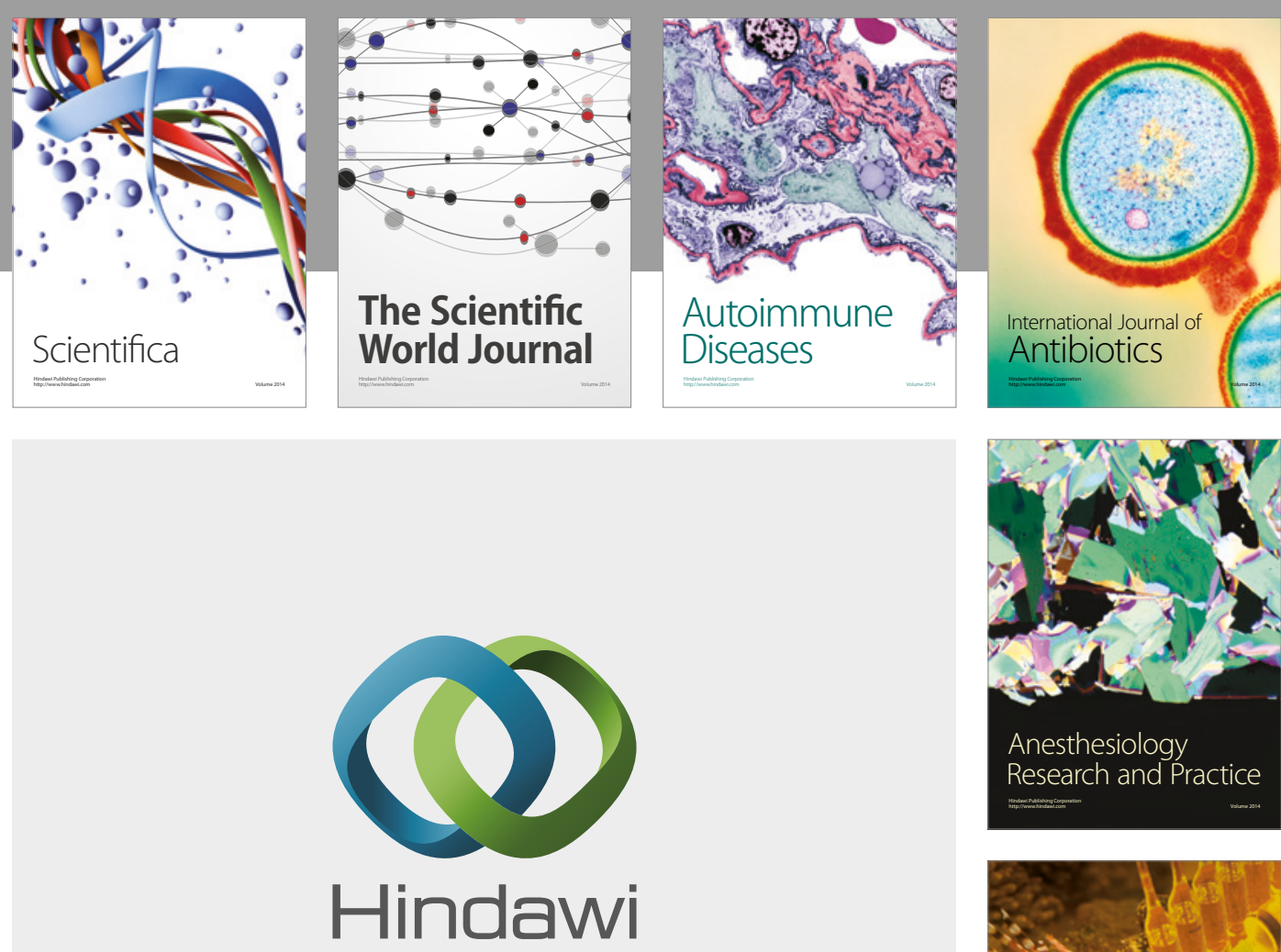

Submit your manuscripts at

https://www.hindawi.com
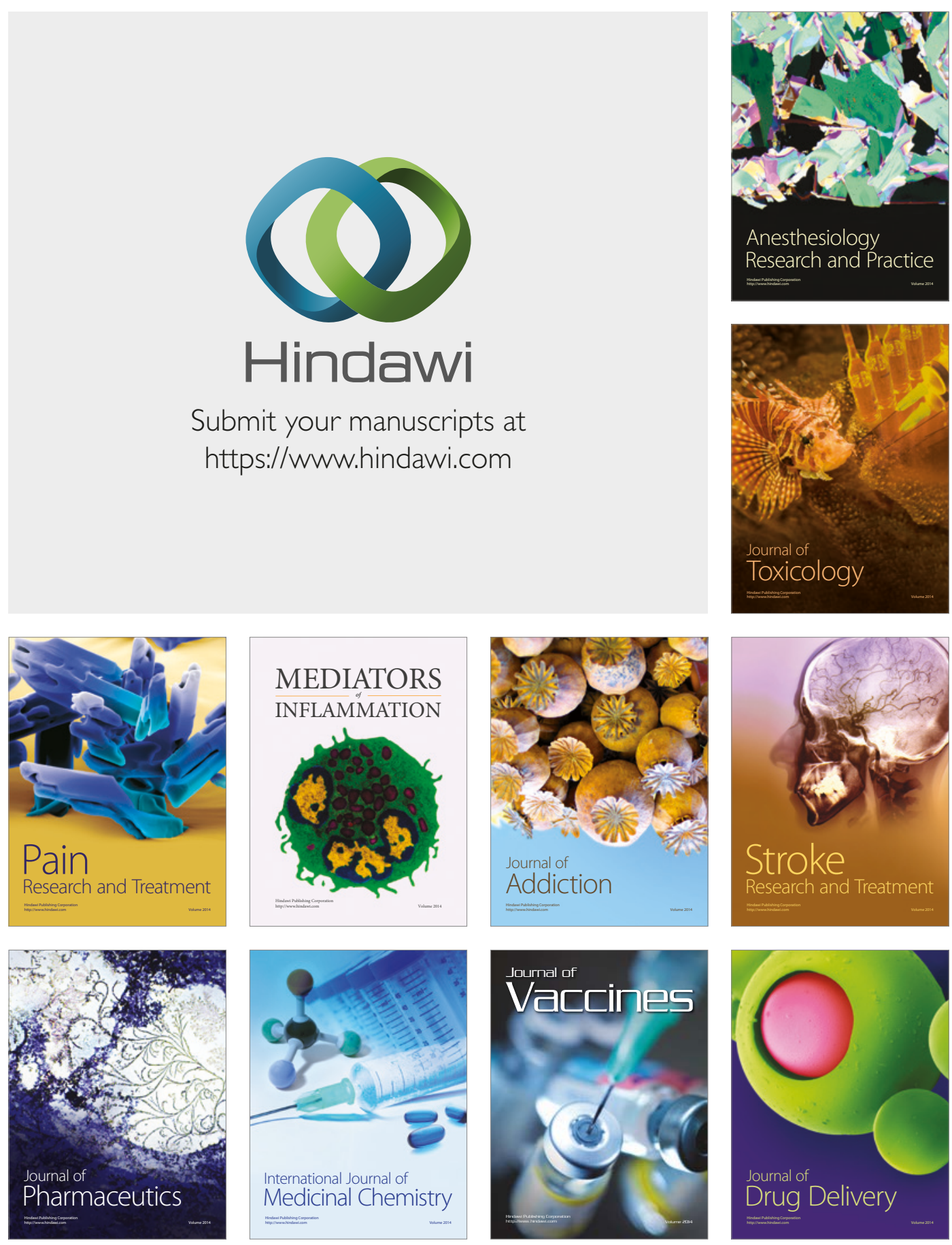